\title{
Transnational Education in Sino-foreign Cooperative Universities: Modes, Benefits and Concerns
}

\author{
Jieming Ma, Chili Li, and Minming Gu
}

\begin{abstract}
China recently has become an increasingly popular market for transnational education ventures. A number of Sino-foreign cooperative universities - legally independent entities formed as joint ventures between Chinese universities and international institutions - have been developed during the last two decades. Meanwhile, frequent controversial conversations are occurring about what benefits the transnational education could bring to students and how to support effective transnational teaching. The most basic modes of transnational education delivery are introduced. Moreover, this paper critically reflects on the benefits of transnational education for students and identifies vital issues that demand our serious consideration about transnational teaching.
\end{abstract}

Index Terms-Sino-foreign cooperative university, transnational education, higher education, reflection, culture.

\section{INTRODUCTION}

The transitional education is increasingly popular and has become one of the most important components of the international high education landscape [1].

However, a remarkable terminological and conceptual confusion exists on the term transnational education. Many of these descriptions for transnational education include words or phrases such as collaborative provision, international education, overseas education, off-campus education, external program, etc. The Global Alliance for Transnational Education (GATE) defines transnational education as: "Any teaching or learning activity in which the students are in a different country (the host country) to that on which the institution providing the education is based (the home country). This situation requires that national boundaries be crossed by information about the education, and by staff and/or education materials (whether the information and the education, and the materials travel by mail, computer network, radio or television broadcast or other means)" [2].

In general, transnational education has the following features:

Manuscript received January 9, 2019; revised June 2, 2019. This research was funded by Xi'an Jiaotong-Liverpool University under Teaching Development Fund TDF 17/18-R16-111, and Research Project of Professional Competence Research Committee-Higher Education Association of Jiangsu Province, China, grant number ZY2018D020.

Jieming Ma is with the Department of Computer Science and Software Engineering, Xi' an Jiaotong Liverpool University, Suzhou, Jiangsu Province, China (e-mail: jieming.ma@xjtlu.edu.cn).

Chili Li is with the School of Foreign Languages, Hubei University of Technology; Wuhan, Hubei Province, China (e-mail: lichili@hbut.edu.cn).

Minming Gu is with the School of Electronic and Information, Suzhou University of Science and Technology; Suzhou, Jiangsu Province, China (e-mail: gmm@usts.edu.cn).
- Learners are located in a country different from the one where the awarding institution is based [3]

- The program is taught partly or wholly offshore (distance education programs are included only when there is a formal agreement that an overseas institution/organization participates in their delivery) [1].

- Students will receive foreign diplomas when they successfully complete their studies [4].

There are about 30 million students currently enrolled in Chinese higher education institutions, evidencing a huge education market. Since the 1980s, Chinese higher education has developed rapidly and obtains the largest higher education system in the world in terms of degrees awarded every year. However, China's modern higher education system is a relatively recent development, especially compared with that of the West [2]. After joining the World Trade Organization, China strives to improve the education quality of their higher education by encouraging foreign universities to offer courses to local students. An increasing number of foreign universities have been allowed to set up campuses in China under a cautious way with constant monitoring of results. Table I lists the nine Sino-foreign cooperative universities in China, including Xi'an Jiaotong-Liverpool University (XJTLU), University of Nottingham Ningbo China (UNNC), Beijing Normal University-Hong Kong Baptist University United International College (BNU-HKBU), New York University Shanghai (NYUS), Wenzhou-Kean University (WKU), Duke Kunshan University (DKU), Chinese University of Hong Kong, Shenzhen (CUHKS), Guangdong Technion-Israel Institute of Technology (GTIIT) and Shenzhen MSU-BIT University (MSU-BIT). Most of these Chinese host universities are ranked as 985 project universities or 211 project universities (Xi'an Jiaotong University, Wuhan University, Beijing Normal University, East China Normal University, and Beijing Institute of Technology are on both 985 and 211 project lists). It is observed that most Chinese host institutions are more likely to partner with higher ranked foreign universities which have a longer history. The university-level collaborative projects provide many opportunities for the two host universities to learn from each other. Meanwhile, foreign universities can also widen their international profile by offering their study programs in collaboration with local partner institutions.

This paper aims to critically reflect on the benefits and challenges of transnational education for students, teaching staff and the university, as well as learning and teaching practice in light of a diverse student body within a transnational context. 
TABLE I: NINE SINO-FOREIGN COOPERATIVE UNIVERSITIES IN CHINA

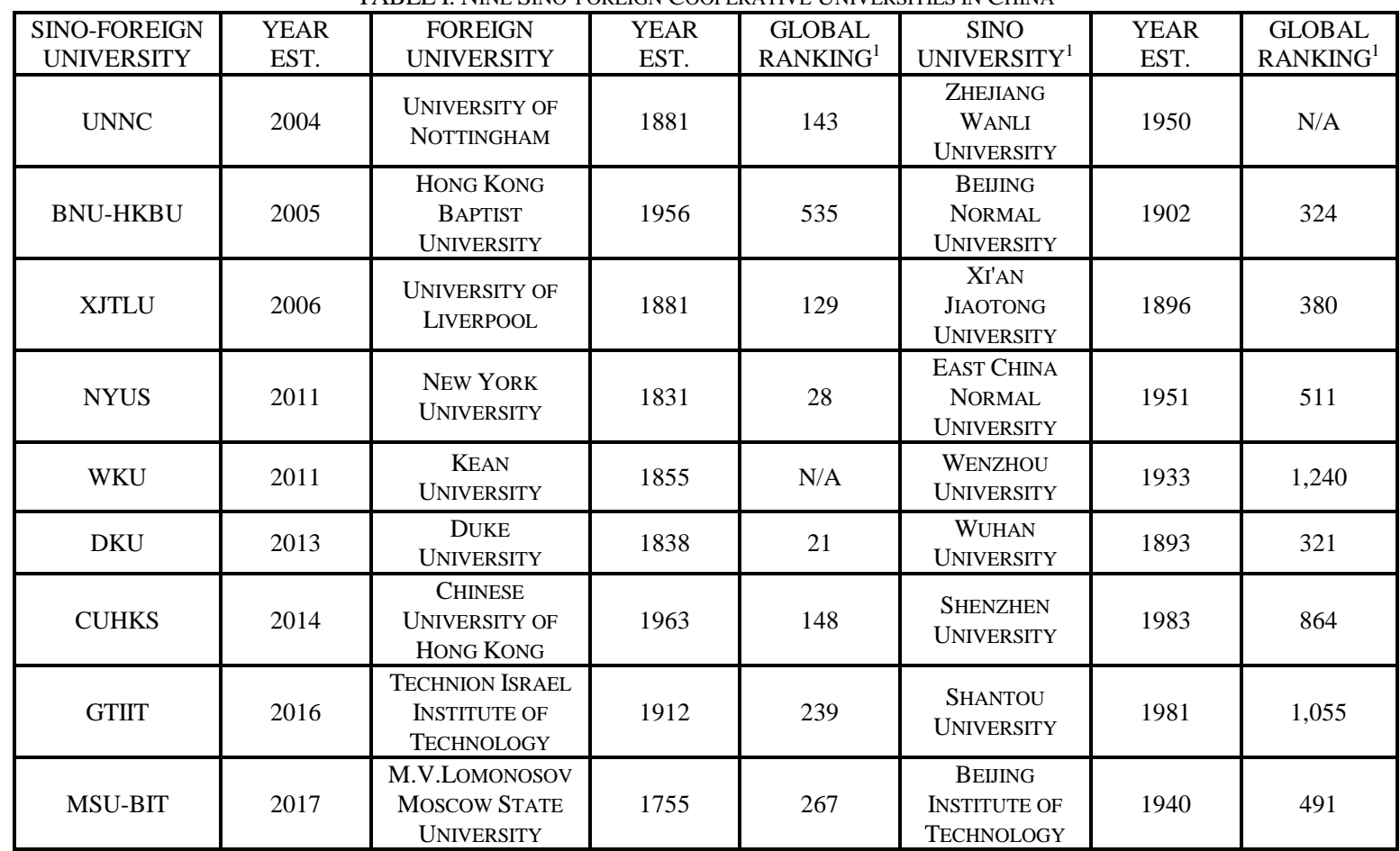

1 U.S. NEWS 2018 GLOBAL RANKING (SOURCE:U.S.NEWS \& WORLD REPORT, BEST GLOBAL UNIVERSITY RANKINGS, 2018, WWW.USNEWS.COM/EDUCATION/BEST-GLOBAL-UNIVERSITIES/RANKINGS)

\section{Modes of Transnational EdUCATION DELIVERY}

Due to the complexity of transnational education in practice, it is hard to develop a consistent methodology to define all the transnational education activities. Mellors-Bourne et al. [5] conclude three most basic modes of transnational education delivery as follows:

1) Physical presence: a higher education institution from the home country establishes a fully-fledged branch campus, study center, or flying faculty in the host country to deliver courses and programs to students.

2) Distance learning: a higher education institution from the home country offer courses and programs via internet, computers, televisions, radios, video conferencing, virtual blackboard or other methods within or beyond the national boundaries. Under this mode, some face-to-face lectures, workshops or other forms of learning activities are arranged to students through a local partner or study center.

3) Local delivery: a higher education institution from the home country authorizes a partner (usually with a locally based higher education provider) in the host country to deliver courses and programs. The qualification will be awarded by the home country's institution. All activities on teaching, management, and assessment are held in line with the regulations and policies of both host and home countries. For instance, the coursework and final exam papers, as well as assessments, are moderated by the academic staff at the home university.

As shown in Fig. 1, the transnational education programs usually blend all the three modes. The blending methodology varies according to a good number of factors regarding country, partnership, student, culture, subject, price, policies, etc.

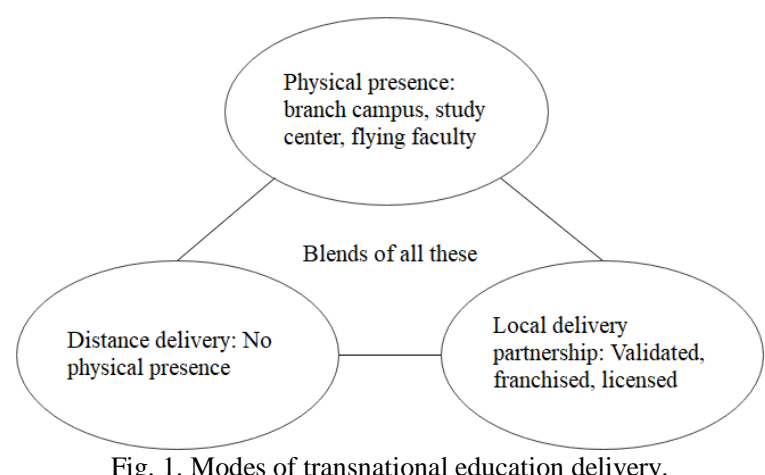

Fig. 1. Modes of transnational education delivery.

\section{BENEFITS OF TRANSNATIONAL EDUCATION FOR STUDENTS}

Transitional education provides Chinese students from their home institutions the opportunity to have a foreign education experience. Courses offered at the host country's institution are normally taught in English. "As transnational education continues to be the driving force of the internationalization of higher education, English as an academic lingua franca remains important in ensuring its success," says Dr Stuart Perrin, Director of the Language Center at XJLTU. Therefore, students will experience maximally different from home campus.

Culture shock is a common phenomenon for the students studying abroad. It refers to a transitional phenomenological experience encountered by individuals since they find themselves unable to use known and familiar cultural references to understand, convey and validate central aspects of their identity in a new culture [6]. The Sino-foreign cooperative university delivers a foreign education system in China and most of the enrolled students receive foreign education experience in their home country. Under the education mode, domestic students will learn the social rules 
and expectations quickly and develop supportive relationships. This allows them to experience less culture shock.

Education quality is the most important concern of students. Sino-foreign cooperative universities use the same curriculum as that of their foreign host universities. The established quality assurance system normally aligns with the international education standards for program and curriculum development and meets the requirements of the Ministry of Education of China. Professor Adam Cross, associate dean of International Business School Suzhou at XJTLU, emphasized the School's efforts in staff training and teaching approaches to meet British assessment standards. He said: "XJTLU's academic staff are from across the world and they have diverse educational backgrounds. We need to guarantee that they can understand and become familiar with the British quality assurance system through training and let them carry out teaching activities under the rules within the system. This is very important for quality assurance."

A study was made on Sino-foreign cooperative university pathways after graduation in [1]. Table II shows the results comparing the different paths taken by students in 2017 . Three-quarters of the graduates of Sino-foreign cooperative universities pursue further study. There are many reasons behind the phenomenon. The most important reason is that these students' English proficiency is usually good, especially oral English and spoken English. Moreover, their foreign education experience enhanced international perspectives, sometimes known as global-mindedness, such as increased understanding of cultural differences. According to XJTLU 2015 Graduates Report, 83.28 percent of our students went onto further study at universities including Oxford, Cambridge and Imperial College London in the United Kingdom, Chicago, Columbia and Cornell in the United States and the Swiss Federal Institute of Technology Zurich. Cooperative universities have been recognized as a bridge for a student is interested in studying abroad for a graduate degree in the future.

TABLE II: SINO-FOREIGN COOPERATIVE UNIVERSITY PATHWAYS AFTER

\begin{tabular}{|l|l|l|l|l|l|}
\hline $\begin{array}{l}\text { SINO-FOREIGN } \\
\text { COOPERATIVE } \\
\text { UNIVERSITY }\end{array}$ & UNNC & $\begin{array}{c}\text { BNU } \\
\text {-HKBU }\end{array}$ & XJTLU & NYUS & WKU \\
\hline FURTHER STUDY & 1,005 & 744 & 1,677 & 72 & 116 \\
\hline WEIGHT & $83 \%$ & $63 \%$ & $82 \%$ & $51 \%$ & $55 \%$ \\
\hline EMPLOYED & 174 & 269 & 349 & 69 & 82 \\
\hline WEIGHT & $14 \%$ & $23 \%$ & $17 \%$ & $49 \%$ & $39 \%$ \\
\hline NOT DECIDED & 32 & 160 & 10 & 0 & 14 \\
\hline WEIGHT & $3 \%$ & $14 \%$ & $0 \%$ & $0 \%$ & $7 \%$ \\
\hline $\begin{array}{l}\text { TOTAL NUMBER } \\
\text { OF GRADUATES }\end{array}$ & 1,211 & 1,173 & 2,036 & 141 & 212 \\
\hline
\end{tabular}

\section{ISSUES IN TRANSITIONAL EDUCATION}

The crossing of cultural, linguistic, legislative borders makes teaching and learning in transitional education extremely complex. In the teaching practice, there are a good number of challenging aspects related to learning shock, language barrier, cultural difference.

\section{A. Learning Shock}

Learning shock mainly describes the challenges inherent within the learning experience itself. In [7], learning shock is defined as follows: "experiences of acute frustration, confusion and anxiety experienced by some students. These students find themselves exposed to unfamiliar learning and teaching methods, bombarded by unexpected and disorienting cues and subjected to ambiguous and conflicting expectations". Since foreign teaching methodologies are adopted in transitional education, learning shock is inevitable in their study. There are many forms of culture shock in practice. For example, many Chinese students are used to memory-based learning, but they may easily get confused when dealing with case studies where there is no single approach to address problems. As another example, students who are used to following teachers' instructions may also feel overwhelmed in self-learning.

Interaction between individuals (e.g. sharing a concern or a passion for something they do and learn how to do it better) would be a positive approach to enhance learning [7]. Joint activity, shared information and mutual help are of importance in transitional education.

In schools, it is hard to find a common context that allows students from different backgrounds to develop common systems of understanding. Teaching and learning via joint activity is cross-cultural and probably "hard-wired." Joint activity between teacher and students may bring a possible common context of experience. In addition to joint activity, shared information plays an important role in learning. Information sharing is regarded as a way of aiding problem-solving and improving operational effectiveness. It ensures teachers and students both to understand the meaning of the communications. Cooperation promotes the development of prosocial and altruistic behaviors, which not only enables students to help each other within a group, but also stimulates interindividual contacts and mutual relations between students.

\section{B. Language Barrier}

Language competency is badly needed in cross-cultural communication. The learning process is inseparable from language: from everyday social language to formal academic language. The current way that Chinese students tend to learn English is that they memorize vocabulary and grammatical structures and then have vocabulary and grammatical structure tests. Through this mode, students can graduate with a level of English but actually can't communicate or use that English in a practical way.

To help Chinese students fit in the international learning environment, many Sino-foreign cooperative universities, such as XJTLU, use the extra year for their freshmen to complete a year of English study and Mathematics learning and start the degree program in the second year. The English teaching focuses on the idea of learning to use English in an applicable, discipline-relevant way. In addition to the first year of study, language development can be taken at various 
aspects - class instruction, group discussions, writing assignments, etc. The development of language and literacy as a metagoal also applies to the specialized language genres required for the study of science, mathematics, history, art, and literature. Language barrier can be solved by learning language and styles of writing that can be used within the discipline a student is studying, as well as, ultimately, in their future career area.

\section{Culture Difference}

Sino-foreign cooperative universities are also attracting an increasing number of international students who want to study in China. In 2012, XJTLU had only 14 international students, but the number has now risen to about 700 . Differences between Chinese and foreign students cannot be ignored in a truly international university. Culture is a pattern of thinking, feeling and acting [8]-[11]. A piece of research was conducted to present cultural distance index values of four broad geographic regions [10], [12]. As seen in Table III, China has a high psychic distance from western countries such as United States, United Kingdom and Canada. This indicates that there are substantial cultural differences between western countries and China. There are many reasons which cause the differences. For example, Chinese students rarely express their views in class since they were often taught in large groups in the fundamental education stage. In addition, most of Chinese students are used to teaching-centered learning environment while student-centered learning is the acceptable approach for most of western students. While fully acknowledging the culture difference, the following cultural knowledge is required for effective transnational teaching:

- what are local cultures (e.g. political, legal and economic environment);

- what are social, cultural and educational backgrounds of students;

- how teachers' cultures affect the way of thinking, feeling and acting;

- and how cultures affect the way of communication.

Developing the notion of community, club or organization may be a good approach to gain the cultural knowledge. In XJTLU, there are more than 120 organizations centered on art sports, entrepreneurship, social service, academia and science. They organize a large number of events, including debating competitions, singing groups, English Corner, book discussion, culture lectures, speaking competitions, festival celebrations, film screenings, TV series discussions, a student-run English newsletter and theatre performances, etc. The focus of these activities is to provide students with opportunities to improve their English skills and to know each other. There is also an emphasis on making friends, developing new skills and learning about the rest of the world.

\section{CONCLUSION}

By capturing the essence of both prestigious parent universities, Sino-foreign cooperative universities, as well as their transitional education modes, have shown many advantages for students. The transitional education mode creates an internationalized educational environment through an internationalized curriculum, a diverse body of academic staff and an increasingly diverse student body, so that local students have an opportunity to gain a foreign education experience. Based on the learning and teaching practice, the most challenging aspects of transitional education, learning shock, communication styles, and cultural differences have been identified. This article emphasized the effects of learning styles, language training, and culture knowledge in transitional teaching.

TABLE III: SAMPLE COUNTRIES WITH CULTURAL DistANCE INDEX VALUES

\begin{tabular}{|c|c|c|c|}
\hline Country & $\begin{array}{c}\text { Cultural } \\
\text { Distance }\end{array}$ & Country & $\begin{array}{c}\text { Culture } \\
\text { Distance }\end{array}$ \\
\hline China & 29.2 & Ireland & 1.7 \\
\hline Indonesia & 18.3 & Italy & 2.2 \\
\hline Japan & 15.2 & Canada & 0.6 \\
\hline Malaysia & 23.6 & Mexico & 17.6 \\
\hline Philippines & 15.7 & United States & 0.1 \\
\hline $\begin{array}{c}\text { Rep of } \\
\text { Korea }\end{array}$ & 20.3 & Argentina & 9.2 \\
\hline Singapore & 19.3 & Brazil & 12.3 \\
\hline Thailand & 16.5 & Chile & 20.7 \\
\hline Netherlands & 5.5 & Colombia & 23.5 \\
\hline Portugal & 21.2 & Ecuador & 27.4 \\
\hline Spain & 8.6 & Ghana & 16.3 \\
\hline Sweden & 8.8 & India & 9.7 \\
\hline $\begin{array}{c}\text { United } \\
\text { Kingdom }\end{array}$ & 0.6 & Iran & 9.3 \\
\hline Austria & 6.3 & Israel & 7.1 \\
\hline Denmark & 7.3 & Kenya & 12.2 \\
\hline Finland & 4.7 & Nigeria & 16.3 \\
\hline France & 6.1 & Pakistan & 17.3 \\
\hline Germany & 1.7 & Turkey & 13.6 \\
\hline
\end{tabular}

\section{CONFLICT OF INTEREST}

The authors declare no conflict of interest.

\section{AUTHOR CONTRIBUTIONS}

Jieming Ma and Chili Li conducted the research; Minming $\mathrm{Gu}$ analyzed the data; Jieming Ma and Chili Li wrote the paper; all authors had approved the final version.

\section{ACKNOWLEDGMENT}

The authors would like to thank the reviewers for all of their careful, constructive and insightful comments in relation to this work.

\section{REFERENCES}

[1] X. Lu. Transnational Education: Sino-Foreign Cooperative Universities in China. World Education Services. [Online]. Available: https://wenr.wes.org/2018/08/sino-foreign-cooperative-universities

[2] Global Alliance for Transnational Education [GATE], Certificate manual, Washington, 1997.

[3] J. McNamara and J. Knight, "Transnational education data collection systems: awareness, analysis, action,” The British Council, 2015, pp. $1-59$.

[4] UNESCO and Council of Europe. (2001). Code of good practice in the provision of transnational education. Bucharest: UNESCO-CEPES [Online]. http://www.cepes.ro/hed/recogn/groups/transnat/code.htm 
[5] R. Yang, "Transnational higher education in China: Contexts, characteristics and concerns," Australian Journal of Education, vol. 52 , no. 3, pp. 272-286, 2008.

[6] R. Mellors-Bourne, J. Fielden, N. Kemp, R. Middlehurst, and S. Woodfield, "The value of Transnational Education to the UK," Careers Research \& Advisory Centre (CRAC) Ltd, 2014.

[7] H. Cameron and C. Kirkman, "Managing culture shock for first year international students entering Australian universities," presented at First Year in Higher Education Conference, University of Queensland, St Lucia, Australia, 2010, June.

[8] E. Wenger, Communities of Practice: Learning, Meaning, and Identity, New York: Cambridge University Press, 1998, pp. 1-15.

[9] D. S. Griffith, D. Winstanley, and Y. Gabriel, "Learning shock: The trauma of return to formal learning," Management Learning, vol. 36, pp. 275-297, 2005

[10] G. Sherriff, P. Brewer, and P. Liesch, "The influence of regionalization and cultural distance on the direction of exports," Journal of Asia-Pacific Business, vol. 11, no. 2, pp. 78-98, 2010.

[11] G. Jusdanis, "Beyond national culture?" Boundary, vol. 22, pp. 23-59, 1995.

[12] R. Fletcher and J. Bohn, "The impact of psychic distance on the internationalisation of the Australian firm," Journal of Global Marketing, vol. 12, no. 2, pp. 47-68, 1998.

Copyright $\odot 2019$ by the authors. This is an open access article distributed under the Creative Commons Attribution License which permits unrestricted use, distribution, and reproduction in any medium, provided the original work is properly cited (CC BY 4.0).

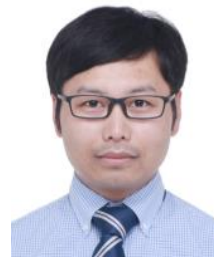

Jieming Ma received the MSc degree in advanced microelectronic systems engineering from the University of Bristol, UK, in 2010, and received the $\mathrm{PhD}$ degree in computer science from the University of Liverpool, UK, in 2014. From 2015 to 2017, he was a lecturer at the Suzhou University of Science and Technology, China. He is currently working as a lecturer at the Xi'an Jiaotong-Liverpool University, China. His current research interests lie in the field of higher education, intelligent optimization, machine learning and applications.

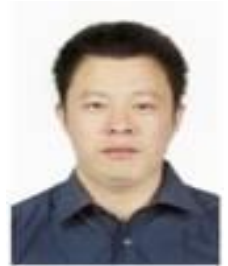

Chili $\mathbf{~} \mathbf{L i}$ is associate professor of applied linguistics at the School of Foreign Languages, Hubei University of Technology, China. He obtained his doctorate in applied linguistics from School of English, the University of Liverpool, UK. His research interests include applied linguistics and EAP teaching in the Chinese EFL context. He has published on both Chinese and international journals such as SYSTEM, Asian EFL Journal, and Chinese Journal of Applied Linguistics.

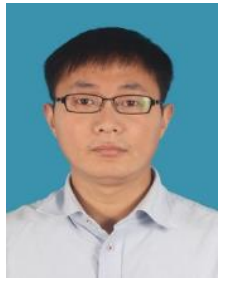

Minming Gu received the master degree in instrumentation engineering from Nanjing Forest University, Nanjing, China, in 2013.

$\mathrm{He}$ is a lecturer at Suzhou University of Science and Technology. His current research interests include IOT, edge computing and higher education. 